\title{
Enhanced Recovery Protocol Reduces Transfusion Requirements and Hospital Stay in Patients Undergoing an Elective Arthroplasty Procedure
}

\author{
Kirsten Juliette de Burlet, ${ }^{1}$ James Widnall, ${ }^{1}$ Cefin Barton, ${ }^{1}$ \\ Veera Gudimetla, ${ }^{2}$ and Stephen Duckett ${ }^{1}$ \\ ${ }^{1}$ Department of Orthopaedic Surgery, Leighton Hospital, Crewe CW1 4QJ, UK \\ ${ }^{2}$ Department of Anaesthetics, Leighton Hospital, Crewe CW1 4QJ, UK \\ Correspondence should be addressed to Kirsten Juliette de Burlet; kjdeburlet@gmail.com
}

Received 30 December 2015; Accepted 17 March 2016

Academic Editor: Padhraig O'Loughlin

Copyright ( $) 2016$ Kirsten Juliette de Burlet et al. This is an open access article distributed under the Creative Commons Attribution License, which permits unrestricted use, distribution, and reproduction in any medium, provided the original work is properly cited.

Background. Enhanced recovery (ER) for elective total hip or total knee replacement has become common practice. The aim of this study is to evaluate the impact of ER on transfusion rates and incidence of venous thromboembolism (VTE). Methods. A comprehensive review was undertaken of all patients who underwent primary hip or knee arthroplasty surgery electively between January 2011 and December 2013 at our institution. ER was implemented in August 2012, thus creating two cohorts: the traditional protocol (TP) group and the ER group. Outcome measurements of length of stay, postoperative transfusion, thromboembolic complications, and number of readmissions were assessed. Main Findings. 1262 patients were included. The TP group contained a total of 632 patients and the ER group contained 630 patients. Postoperative transfusion rate in the ER group was reduced with $45 \%$ $(P \leq 0.05)$. There was no statistical difference in postoperative VTE complications. The length of stay was reduced from 5.5 days to 4.8 days $(P<0.05)$. Conclusions. There was no difference in the number of readmissions. ER has contributed to a significant decrease in transfusions after elective arthroplasty surgery, with no increase in the incidence of thromboembolic events. Furthermore, it has significantly reduced inpatient length of stay.

\section{Introduction}

Several studies advocating enhanced recovery (ER) or fasttrack protocol for elective total hip or total knee replacement have been published and it is becoming the common practice for arthroplasty surgery in most hospitals in the United Kingdom. ER protocols are commonly developed and tailored to given units routine practice, but common themes include preoperative patient education, perioperative administration of tranexamic acid and defined standards for anaesthesia and postoperative analgesia, fluid management, and early mobilisation. This multidisciplinary approach has been proven to be beneficial for the patient with a significant reduction of early postoperative complications and a reduction in length of stay (LOS) [1-5].
Intravenous administration of tranexamic acid prior to surgery has been proven to reduce perioperative blood loss and postoperative transfusion rate $[6,7]$. There have been historic concerns regarding increased risk of thromboembolism with its use but several recent studies appear to contradict this view [8].

Reducing LOS with a given ER protocol has obvious potential cost benefits and there is increasing evidence that it does not lead to an increase in the number of readmissions [13]. Furthermore, a combined multidisciplinary approach and comprehensive preoperative patient education have resulted in higher patient satisfaction scores [1,9-11].

Our aim was to evaluate the ER protocol in our hospital. Our main outcome measures were transfusion rate, number of VTE complications, and overall LOS. 
TABLE 1: Traditional protocol versus enhanced recovery protocol.

\begin{tabular}{|c|c|c|}
\hline & Traditional protocol & Enhanced recovery protocol \\
\hline Preoperative & $\begin{array}{l}\text { (i) Generic patient } \\
\text { education }\end{array}$ & $\begin{array}{l}\text { (i) Patient education and emphasis on active patient participation-“joint school" } \\
\text { (ii) Energy drink } 2 \text { hrs before surgery } \\
\text { (iii) Premedication: omeprazole } 20 \mathrm{mg} \text { PO and gabapentin } 300 \mathrm{mg} \text { PO }\end{array}$ \\
\hline Perioperative & $\begin{array}{l}\text { (i) General or spinal } \\
\text { anaesthesia according to } \\
\text { anaesthetist's preferences }\end{array}$ & $\begin{array}{l}\text { (i) Spinal anaesthesia: } 3 \mathrm{~mL} \text { of } 0.5 \% \text { levobupivacaine } \\
\text { (ii) Antibiotics: } 1.2 \mathrm{~g} \text { co-amoxiclav } \\
\text { (iii) Tranexamic acid } 1 \mathrm{~g} \text { IV } \\
\text { (iv) Medication: Paracetamol } 1 \mathrm{~g} \mathrm{IV} \text {, Ondansetron } 4 \mathrm{mg} \text { IV, Dexamethasone } 6.6 \mathrm{mg} \text { IV } \\
\text { (v) Local infiltration: } 100 \mathrm{~mL} \text { of } 0.2 \% \text { ropivacaine with } 1 \text { in } 100000 \text { adrenaline and } \\
50 \mathrm{mLs} \text { of plain } 0.2 \% \text { ropivacaine for skin and subcutaneous tissues }\end{array}$ \\
\hline Postoperative & $\begin{array}{l}\text { (i) Enoxaparin } 48 \text { hrs after } \\
\text { surgery } \\
\text { (ii) Analgesia and fluid } \\
\text { management according to } \\
\text { consultants preferences } \\
\text { (iii) Involving } \\
\text { femoral/sciatic nerve } \\
\text { blocks and PCAs for all } \\
\text { patients } \\
\text { (iv) Physiotherapy without } \\
\text { a specific postoperative } \\
\text { protocol-mobilised when } \\
\text { nerve blocks wear off at } \\
\text { variable duration }\end{array}$ & $\begin{array}{l}\text { (i) Enoxaparin started the same day } \\
\text { (ii) Multimodal analgesia management by acute pain team and ward staff using } \\
\text { oxycodone regime. No PCA/nerve blocks } \\
\text { (iii) Fluid monitoring } \\
\text { (iv) Early mobilisation with physiotherapy - the same day or early next day }\end{array}$ \\
\hline
\end{tabular}

\section{Materials and Methods}

The ER protocol was officially implemented in our institution in August 2012. Initially a pilot protocol was implemented in May 2012 based on the existing protocol from the Robert Jones and Agnes Hunt Orthopaedic Hospital in Oswestry, United Kingdom. The pilot protocol was audited and after minor adjustments the current protocol (shown in Table 1) was implemented. Prior to implementation, there was a formal educational process for all staff involved including physiotherapist, nursing staff, and occupational therapists. For this study we retrospectively included all patients who underwent an elective total hip or total knee replacement between January 2011 and December 2013. Any revision arthroplasty procedures were excluded. Thus, two cohorts were created in accordance with their date of operation: the traditional protocol (TP) group and the ER group. We retrospectively collected all the data from operation notes, discharge letters, laboratory, and radiology reports. Ninetyday complication and readmission rates were included.

The preoperative management, perioperative management, and postoperative management of the TP and the ER protocol are shown in Table 1. Patients were initially assessed in the orthopaedic outpatient department, where they were counselled about what to expect during their inpatient journey. They also received a patient information leaflet. Postoperative analgesia included OxyContin 10-20 mg PO every 12 hours for the first three days, Gabapentin $300 \mathrm{mg}$ at night for five days, Naproxen every 12 hours (if not contraindicated, eGFR $<60 \mathrm{mLs} / \mathrm{min} / \mathrm{m}^{2}$ ), omeprazole $20 \mathrm{mg}$ PO for 5 days (continued when NSAID was continued), and Paracetamol $1 \mathrm{~g}$ four times a day IV which was changed to oral after $24 \mathrm{hrs}$.

All patients received antibiotic prophylaxis within 60 minutes prior to incision. Co-amoxiclav (Augmentin ${ }^{\circledR}$ ) $1.2 \mathrm{~g}$ was administered intravenously according to our hospital policy. Patients who were allergic to penicillin received Teicoplanin (Targocid ${ }^{\circledR}$ ) 600 mg IV instead.

The surgical implants used did not change during the study period. All procedures were performed by 5 experienced arthroplasty consultants. No wound drains were used.

Patients were discharged home when the following criteria were met: postoperative pain was well controlled; the individual was able to move independently using appropriate walking aids, voiding urine normally and opening their bowels at least once after surgery. These criteria did not change during our study period. There was a follow-up phone call from the orthopaedic ward 48 hours after discharge to ensure that the patients continued to recover as expected and to give individuals opportunity to express any concerns.

Postoperative blood transfusion was considered when a haemoglobin $(\mathrm{Hb})$ drop of more than $40 \mathrm{~g} / \mathrm{L}$ was seen or when the postoperative $\mathrm{Hb}$ was lower than $80 \mathrm{~g} / \mathrm{L}$ for patients with no cardiovascular history and $90 \mathrm{~g} / \mathrm{L}$ for patients with a significant cardiovascular history. Oral supplementary iron tablets were prescribed when a patient had a moderate $\mathrm{Hb}$ drop of $<30 \mathrm{~g} / \mathrm{L}$ or a postoperative $\mathrm{Hb}$ of $90-110 \mathrm{~g} / \mathrm{L}$.

Comparison between the two cohorts was performed with Student's $t$-test and Chi-square test, and Mann-Whitney $U$ tests were used to analyse differences. Data analyses were performed using SPSS ${ }^{\circledR}$ software (SPSS 20, Chicago, 
TABLE 2: Patient characteristics.

\begin{tabular}{lccc}
\hline & $\begin{array}{c}\text { Traditional } \\
\text { protocol } \\
(n=638)\end{array}$ & $\begin{array}{c}\text { Enhanced } \\
\text { protocol } \\
(n=629)\end{array}$ & $P$ value \\
\hline $\begin{array}{l}\text { Age (mean [SD]) } \\
\text { Gender }\end{array}$ & $69.6[9.1]$ & $69.5[10.2]$ & 0.072 \\
$\quad$ Female (\%) & $352(55.2 \%)$ & $343(54.5 \%)$ & 0.819 \\
$\begin{array}{l}\text { Procedure (\%) } \\
\text { THR }\end{array}$ & $323(50.6 \%)$ & $324(51.5 \%)$ & 0.753 \\
$\quad$ TKR & $315(49.4 \%)$ & $305(48.5 \%)$ & \\
$\begin{array}{l}\text { Length of stay } \\
\text { (mean/median } \\
\text { (range) })\end{array}$ & $5.5 / 4.0(2-92)$ & $4.8 / 4.0(1-41)^{*}$ & $<0.001$ \\
Readmission & $21(3.3 \%)$ & $17(2.7 \%)$ & 0.539 \\
\hline
\end{tabular}

Note: length of stay is in days. There is no significant difference in age, gender, operation, and readmission. There is a significant difference for length of stay, $P=0.001$, using Mann-Whitney's test.

${ }^{*}$ Value is significant.

Illinois, USA). A $P$ value of $<0.05$ was considered statistically significant.

\section{Results}

A total of 1267 patients were included, 638 in the traditional protocol (TP) group and 629 in the enhanced recovery (ER) group. There were no significant differences in age or gender between the two groups and the distributions of THR and TKR were equal between the groups (Table 2). The length of stay (LOS) was significantly shorter in the ER group $(P=$ $0.001)$. There were $21(3.3 \%)$ readmissions in the traditional protocol group and $17(2.7 \%)$ in the ER group; this was not statistically significant.

In total 76 patients received a blood transfusion during the study period (Table 3 ). In the $\mathrm{TP}$ group, the number of transfusions was $49(7.7 \%)$ and in the ER group it was 27 (4.3\%); this was a statistically significant difference $(P \leq$ $0.001)$. Patients undergoing a THR during the study period were more likely to receive a blood transfusion $(n=49$ (7.6\%)) compared to patients who underwent a TKR $(n=$ $27(4.4 \%))(P=0.011)$. There was a drop in the number of patients who underwent a blood transfusion between the TR group and the ER group for both procedures. In the TR group $33(10.2 \%)$ patients who had a THR needed a blood transfusion; this number was 16 (4.9\%) for the ER group. This was also found to be statistically significant difference $(P=0.008)$. For the TKR patients, $19(6.0 \%)$ received a blood transfusion in the TP group and $8(2.6 \%)$ received a blood transfusion in the ER group $(P=0.029)$. The odds ratio for receiving a blood transfusion in the ER group was 0.45 (95\% CI: 0.27 to 0.74 ).

There was no difference in the mean preoperative, postoperative, or discharge haemoglobin level for the patients who underwent a blood transfusion. The number of units transfused was equal between the TP group and the ER group.

Table 4 shows the mean LOS in days per different category. For patients undergoing a THR or TKR the mean
TABLE 3: Transfusion.

\begin{tabular}{lccc}
\hline & $\begin{array}{c}\text { Traditional } \\
\text { protocol } \\
(n=52)\end{array}$ & $\begin{array}{c}\text { Enhanced } \\
\text { protocol } \\
(n=24)\end{array}$ & $P$ value \\
\hline $\begin{array}{l}\text { Procedure }(n(\%)) \\
\text { THR }\end{array}$ & $33(63.5 \%)$ & $16(66.7 \%)$ & 0.008 \\
TKR & $19(36.5 \%)$ & $8(33.3 \%)$ & 0.029 \\
Hemoglobin (g/L) & $118.3[13.0]$ & $125.7[12.7]$ & 0.957 \\
$\quad$ Preop. & $78.3[8.3]$ & $89.9[14.1]$ & 0.021 \\
Postop. & $100.0[7.4]$ & $106.0[11.5]$ & 0.125 \\
$\quad$ Discharge & $2.14[0.6]$ & $2.15[0.6]$ & 0.772 \\
Units (mean) & & & \\
Anticoagulant $(n)$ & $4(8.2 \%)$ & $4(14.8 \%)$ & 0.366 \\
$\quad$ Aspirin/clopidogrel & $10(20.4 \%)$ & $6(22.2 \%)$ & 0.952 \\
$\quad$ Warfarin & & & \\
\hline
\end{tabular}

Note: this table only shows data of the patients who received a blood transfusion in our cohort. Less patients were transfused in the ER group $(P \leq 0.001)$. There was no statistical difference between the other values in this table (Chi-square test).

TABLE 4: Length of stay.

\begin{tabular}{lccc}
\hline & $\begin{array}{c}\text { Traditional } \\
\text { protocol } \\
(n=638)\end{array}$ & $\begin{array}{c}\text { Enhanced } \\
\text { recovery } \\
(n=629)\end{array}$ & $P$ value \\
\hline Operation (mean [SD]) & $5.8[7.0]$ & $4.7[3.3]$ & $<0.001$ \\
THR & $5.2[4.0]$ & $4.9[3.5]$ & 0.012 \\
TKR & $5.1[5.1]$ & $4.5[3.0]$ & $<0.001$ \\
Blood transfusion & $10.3[9.2]$ & $10.8[6.3]$ & 0.416 \\
No & & & \\
Yes & $4.1[1.4]$ & $3.7[4.7]$ & 0.002 \\
Age (yr) & $4.2[2.4]$ & $4.0[2.1]$ & 0.457 \\
$30-50$ & $4.5[3.6]$ & $3.9[1.9]$ & 0.001 \\
$50-60$ & $6.3[7.1]$ & $5.2[4.0]$ & $<0.001$ \\
$60-70$ & $8.4[7.6]$ & $7.0[3.9]$ & 0.372 \\
$70-80$ & & & \\
$80-91$ & $5.4[6.3]$ & $4.6[3.9]$ & $<0.001$ \\
Gender & $5.7[5.2]$ & $4.9[2.9]$ & 0.002 \\
Male &
\end{tabular}

Note: length of stay is a mean value in days. All outcomes are significantly different (Mann-Whitney's test).

LOS dropped significantly ( $P \leq 0.001$ and 0.012 , resp.). However, the most significant drop was seen for the patients undergoing a THR. Patients undergoing a blood transfusion stayed in hospital longer compared to patients who did not undergo a blood transfusion $(P \leq 0.001)$. A correlation between increasing age and a longer LOS was demonstrated. Female patients undergoing a THR or a TKR were more likely to stay in hospital longer $(P=0.001)$. Seventy-one $(5.6 \%)$ patients were discharged to an intermediate care facility; no difference was found in this number between the ER group and TP group. 
TABLE 5: Complications.

\begin{tabular}{lcc}
\hline & $\begin{array}{c}\text { Traditional } \\
\text { protocol } \\
(n=638)\end{array}$ & $\begin{array}{c}\text { Enhanced } \\
\text { protocol } \\
(n=629)\end{array}$ \\
\hline $\begin{array}{l}\text { Thromboembolic complications } \\
\text { PE }\end{array}$ & $2(0.3 \%)$ & $2(0.3 \%)$ \\
DVT & $7(1.1 \%)$ & $5(0.8 \%)$ \\
Other cardiovascular & $2(0.3 \%)$ & $3(0.5 \%)$ \\
complications & $3(0.5 \%)$ & $1(0.2 \%)$ \\
Cerebrovascular complications & & \\
Other complications & $13(2.0 \%)$ & $8(1.3 \%)$ \\
$\quad \begin{array}{l}\text { Pneumonia } \\
\text { Haematoma }\end{array}$ & $2(0.3 \%)$ & $1(0.2 \%)$ \\
Wound infection & $8(1.3 \%)$ & $7(1.1 \%)$ \\
Gastric ulcer & $2(0.3 \%)$ & $1(0.2 \%)$ \\
\hline
\end{tabular}

Note: there is no significant difference for all complications between the traditional protocol and enhanced protocol (Chi-square test).

There was a total observed complications rate of $6.0 \%$ in the TP group and $4.5 \%$ in the ER group, which is illustrated in Table 5. The spread of complications was comparable across both groups. There was no difference in VTE related complications between the groups. During the study period 7 patients died within 90 days after surgery. In the TP group, two patients died of pneumonia, one patient died of the complications after a severe stroke, and one patient died of a cardiac arrest. In the ER group, two patients had a cardiac arrest and one patient died of pneumonia.

\section{Discussion}

This study demonstrates that, since the introduction of our local ER protocol, blood transfusion for patients undergoing elective total hip or total knee replacement has been significantly reduced, without increasing the number of VTE complications. Furthermore, there was a reduction in mean LOS, especially for the patients undergoing a THR, without an increase in the number of readmissions.

The number of blood transfusions dropped significantly in the ER group, with an odds ratio of 0.45 (95\% CI: 0.27 to 0.74 ). This is most likely the result of the combination of tranexamic acid and local adrenaline infiltration. There are multiple studies reporting the benefits of tranexamic acid for reducing blood transfusion rates for patients undergoing elective arthroplasty [12-14]. Although blood transfusions do not seem to be related to an increased mortality rate [15], they are related to a higher rate of wound infection and can lead to severe transfusion reactions $[16,17]$. Furthermore, blood transfusion has a significant associated cost ( $£ 125$ per unit, ref. NHS Blood and Transplant 2012).

The postoperative haemoglobin drop was equal in both the TP group and the ER group. The number of units transfused was also comparable between the groups. This supports the fact that transfusion practice did not change in the study period.
The LOS significantly reduced in the ER group. We found that LOS was associated with certain patient characteristics. In the ER group, patients undergoing a THR stayed for an equal period of time in hospital compared with the TKR group. Before implementation of the protocol the length of stay was, on average, a day longer compared to the TKR patient group. Patients whose postoperative recovery was complicated with severe blood loss requiring a blood transfusion stayed longer in hospital (mean of 10.5 days), compared to the patients who did not receive blood (5.2 days) $(P \leq 0.001)$. Increasing age was directly correlated to prolonged hospital stay; this is in line with other comparable studies $[1,18,19]$. This is most likely directly related to the increased incidence of comorbidities with age and social circumstances. Whilst occupational therapists are members of our arthroplasty MDT, their role between pre-ER protocol and post-ER protocol did not change. They routinely assess patients in the postoperative period to facilitate discharge. This was the case for both patient cohorts. A potential area of improvement to bring down LOS would be to see if this process could be any more efficient. Nevertheless, this study shows clearly that the elderly patient has more benefit from the ER protocol compared to the younger patient.

Females had a longer LOS compared to males, which has been previously shown in other studies $[1,18]$. There is no clear explanation for this finding. Both females and males benefitted equally from the ER approach.

Readmission rates in our study were low $(3.3 \%$ in TP group and $2.7 \%$ in ER group) and there was no difference in the number of readmissions between the two groups $(P=$ 0.327). Compared to similar study designs our readmission rate was remarkably lower $(2.7 \%$ versus $5 \%$, Husted et al., 2008 [1], and 4.8\%, Malviya et al., 2011 [3]). However, our mean LOS was longer compared to other similar studies (4.8 days, ER group, in our study versus 3.8 days, Husted et al., 2008 [1], and 3.7 days, Malviya et al., 2011 [3]).

During the study period the number of VTE complications did not differ between the TP group and the ER group. There are studies which reported a reduced incidence of VTE events in their ER group; this effect is most likely due to the early mobilisation and adequate VTE prophylaxis [2, 4]. There was no significant difference in the incidence of other complications between the TP group and the ER group. There may be a small trend towards fewer complications in the ER group, but this study is underpowered to properly assess this.

Limitations of our study are in the retrospective design. Furthermore, the TP group and the ER group are from different time periods. Although no differences in distribution of the patients were identified and no other changes in treatment for elective arthroplasty were made other than the implementation of the ER protocol, this may be a confounding factor. The reduction in the number of postoperative transfusions in the ER group is most likely due to a combination of local injection of adrenalin, tranexamic acid, and standardised wound management. Tranexamic acid is potentially, given the previously published results, the largest contributing factor to this reduction [6-8]. 
The enhanced recovery protocol compromises multiple factors of which perioperative tranexamic acid, early mobilisation, adequate analgesia monitored by a specialised "pain team," and start of anticoagulation immediately postoperatively are the most important. This study showed a reduction in LOS which is likely to be multifactorial.

In conclusion, our ER protocol led to a significant reduction in postoperative transfusion rate after elective TKR and THR, without an increased incidence of VTE complications. Furthermore, a significant reduction in LOS without an increase in the number of readmissions was seen in the ER group. The reduction in both LOS and blood transfusions has obvious beneficial cost implications.

\section{Competing Interests}

The authors declare that they have no competing interests.

\section{References}

[1] H. Husted, G. Holm, and S. Jacobsen, "Predictors of length of stay and patient satisfaction after hip and knee replacement surgery: fast-track experience in 712 patients," Acta Orthopaedica, vol. 79, no. 2, pp. 168-173, 2008.

[2] S. K. Khan, A. Malviya, S. D. Muller et al., "reduced short-term complications and mortality following enhanced recovery primary hip and knee arthroplasty: results from 6,000 consecutive procedures," Acta Orthopaedica, vol. 85, no. 1, pp. 26-31, 2014.

[3] A. Malviya, K. Martin, I. Harper et al., "Enhanced recovery program for hip and knee replacement reduces death rate: a study of 4,500 consecutive primary hip and knee replacements," Acta Orthopaedica, vol. 82, no. 5, pp. 577-581, 2011.

[4] M. S. Ibrahim, H. Twaij, D. E. Giebaly, I. Nizam, and F. S. Haddad, "Enhanced recovery in total hip replacement: a clinical review," The Bone \& Joint Journal, vol. 95, no. 12, pp. 1587-1594, 2013.

[5] D. B. Auyong, C. J. Allen, J. A. Pahang, J. J. Clabeaux, K. M. MacDonald, and N. A. Hanson, "Reduced length of hospitalization in primary total knee arthroplasty patients using an updated enhanced recovery after orthopedic surgery (ERAS) pathway," Journal of Arthroplasty, vol. 30, no. 10, pp. 1705-1709, 2015.

[6] C. M. Duncan, B. P. Gillette, A. K. Jacob, R. J. Sierra, J. Sanchez-Sotelo, and H. M. Smith, "Venous thromboembolism and mortality associated with tranexamic acid use during total hip and knee arthroplasty," Journal of Arthroplasty, vol. 30, no. 2, pp. 272-276, 2015.

[7] Q. Wu, H.-A. Zhang, S.-L. Liu, T. Meng, X. Zhou, and P. Wang, "Is tranexamic acid clinically effective and safe to prevent blood loss in total knee arthroplasty? A meta-analysis of 34 randomized controlled trials," European Journal of Orthopaedic Surgery and Traumatology, vol. 25, no. 3, pp. 525-541, 2015.

[8] J. Xie, J. Ma, P. Kang et al., "Does tranexamic acid alter the risk of thromboembolism following primary total knee arthroplasty with sequential earlier anticoagulation? A large, single center, prospective cohort study of consecutive cases," Thrombosis Research, vol. 136, no. 2, pp. 234-238, 2015.

[9] S. Jones, M. Alnaib, M. Kokkinakis, M. Wilkinson, A. St Clair Gibson, and D. Kader, "Pre-operative patient education reduces length of stay after knee joint arthroplasty," Annals of the Royal College of Surgeons of England, vol. 93, no. 1, pp. 71-75, 2011.
[10] L. S. Moulton, P. A. Evans, I. Starks, and T. Smith, "Pre-operative education prior to elective hip arthroplasty surgery improves postoperative outcome," International Orthopaedics, vol. 39, no. 8, pp. 1483-1486, 2015.

[11] J. T. Machin, S. Phillips, M. Parker, J. Carrannante, and M. W. Hearth, "Patient satisfaction with the use of an enhanced recovery programme for primary arthroplasty.," Annals of the Royal College of Surgeons of England, vol. 95, no. 8, pp. 577-581, 2013.

[12] E. Irisson, Y. Hémon, V. Pauly, S. Parratte, J.-N. Argenson, and F. Kerbaul, "Tranexamic acid reduces blood loss and financial cost in primary total hip and knee replacement surgery," Orthopaedics \& Traumatology: Surgery \& Research, vol. 98, no. 5, pp. 477-483, 2012.

[13] M. Sukeik, S. Alshryda, F. S. Haddad, and J. M. Mason, "Systematic review and meta-analysis of the use of tranexamic acid in total hip replacement," Journal of Bone and Joint Surgery $B$, vol. 93, no. 1, pp. 39-46, 2011.

[14] S. Alshryda, P. Sarda, M. Sukeik, A. Nargol, J. Blenkinsopp, and J. M. Mason, "Tranexamic acid in total knee replacement: a systematic review and meta-analysis," The Journal of Bone \& Joint Surgery - British Volume, vol. 93, no. 12, pp. 1577-1585, 2011.

[15] J. L. Carson, F. Sieber, D. R. Cook et al., "Liberal versus restrictive blood transfusion strategy: 3 -year survival and cause of death results from the FOCUS randomised controlled trial," The Lancet, vol. 385, no. 9974, pp. 1183-1189, 2015.

[16] N. B. Frisch, N. M. Wessell, M. A. Charters, S. Yu, J. J. Jeffries, and C. D. Silverton, "Predictors and complications of blood transfusion in total hip and knee arthroplasty," Journal of Arthroplasty, vol. 29, no. 9, pp. 189-192, 2014.

[17] S. Engelbrecht, E. M. Wood, and M. F. Cole-Sinclair, "Clinical transfusion practice update: haemovigilance, complications, patient blood management and national standards," Medical Journal of Australia, vol. 199, no. 6, pp. 397-401, 2013.

[18] H. Husted, H. C. Hansen, G. Holm et al., "What determines length of stay after total hip and knee arthroplasty? A nationwide study in Denmark," Archives of Orthopaedic and Trauma Surgery, vol. 130, no. 2, pp. 263-268, 2010.

[19] J. H. Hayes, R. Cleary, W. J. Gillespie, I. M. Pinder, and J. L. Sher, "Are clinical and patient assessed outcomes affected by reducing length of hospital stay for total hip arthroplasty?" Journal of Arthroplasty, vol. 15, no. 4, pp. 448-452, 2000. 


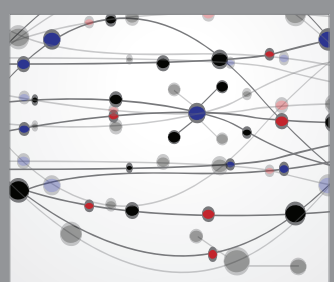

The Scientific World Journal
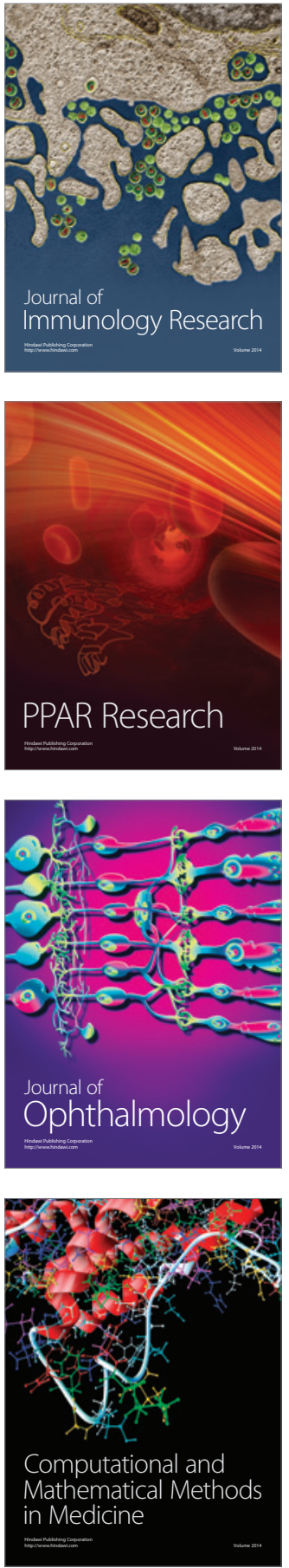

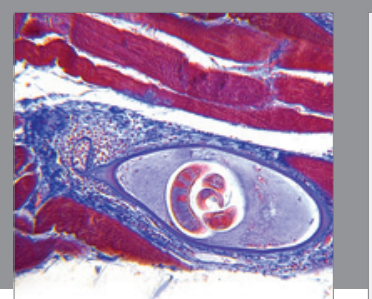

Gastroenterology Research and Practice

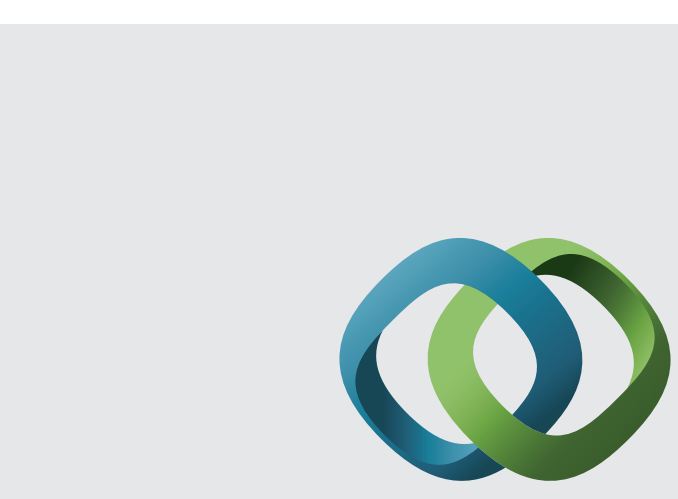

\section{Hindawi}

Submit your manuscripts at

http://www.hindawi.com
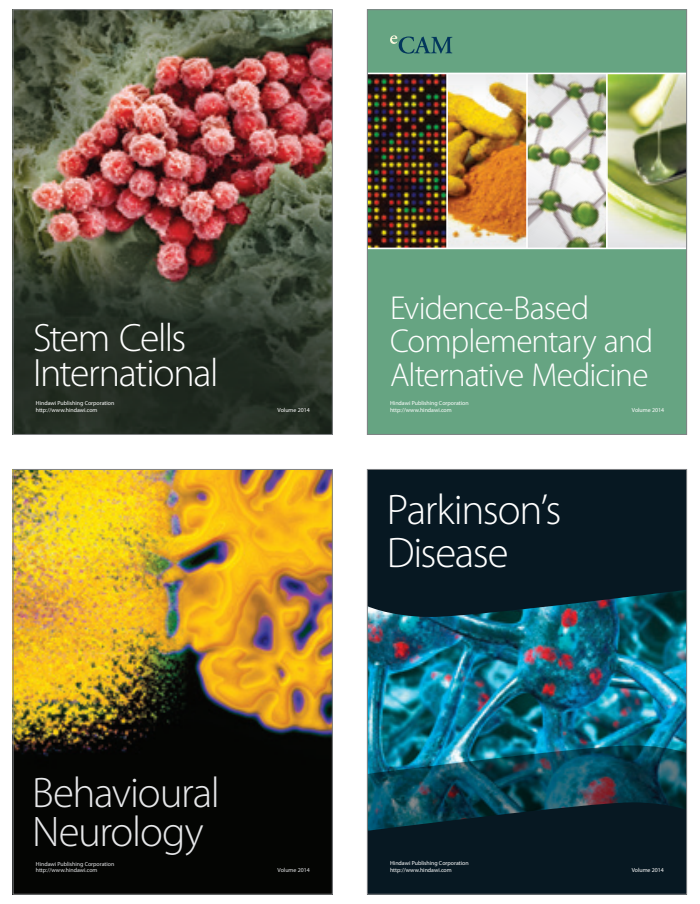
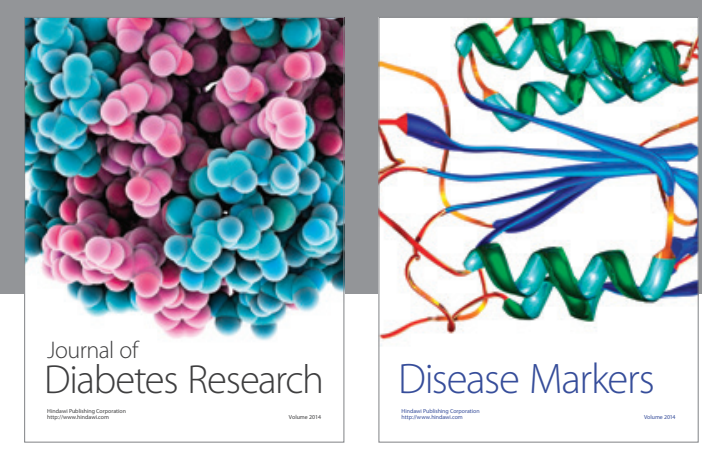

Disease Markers
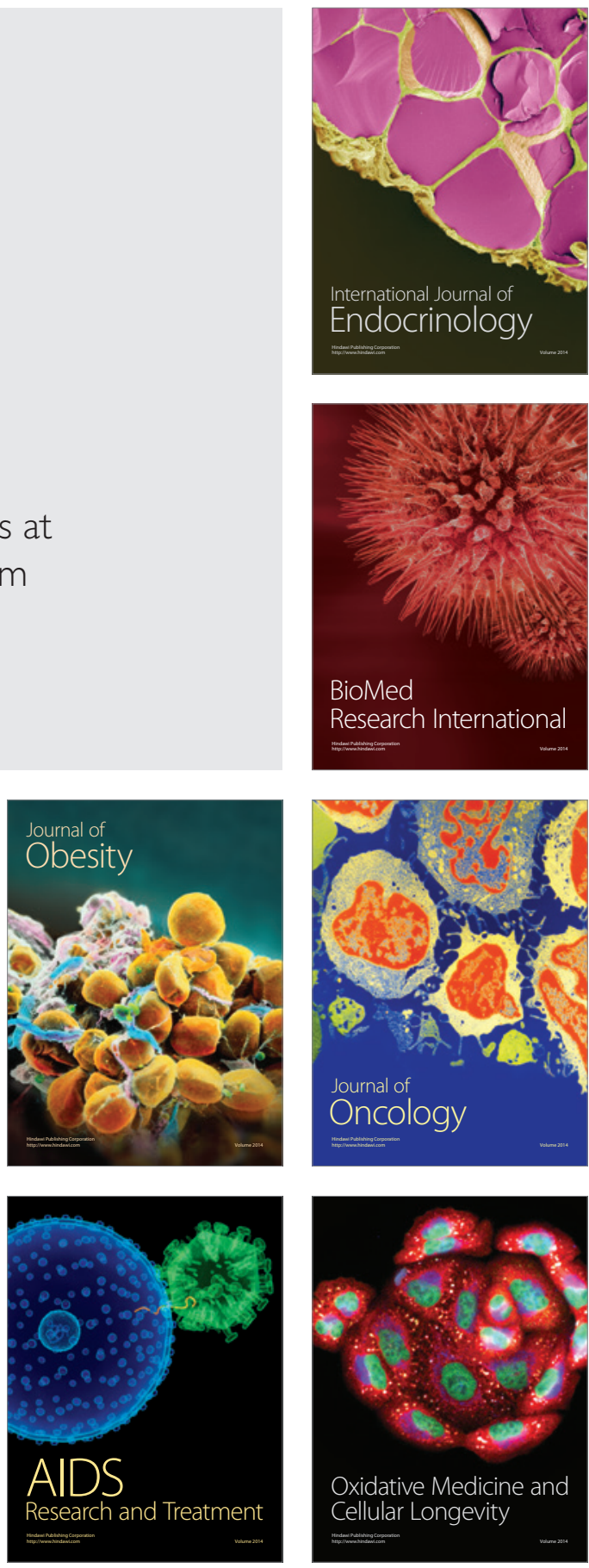